\title{
Initiatives to shorten duration of untreated psychosis: systematic review
}

Brynmor Lloyd-Evans, Michelle Crosby, Sarah Stockton, Stephen Pilling, Lorna Hobbs, Mark Hinton and Sonia Johnson

\section{Background}

Long duration of untreated psychosis (DUP) is common and associated with poor outcomes. Strategies to enhance early detection of first-episode psychosis have been advocated.

\section{Aims}

To evaluate initiatives for early detection of psychosis.

\section{Method}

Systematic review of available evidence on the effectiveness of early detection initiatives to reduce the DUP.

\section{Results}

The review included 11 studies which evaluated 8 early detection initiatives. Evidence suggests that general practitioner education campaigns and dedicated early intervention services do not by themselves reduce DUP or generate more treated cases. Evidence for multifocus initiatives is mixed: intensive campaigns targeting the general public as well as relevant professionals may be needed. No studies evaluated initiatives targeting young people or professionals from non-health organisations.

\section{Conclusions}

How early detection can be achieved is not clear. Evidence is most promising for intensive public awareness campaigns: these require organisation and resourcing at a regional or national level. More good-quality studies are needed to address gaps in knowledge.

\section{Declaration of interest}

None.
Long duration of untreated psychosis (DUP) is associated with poor outcomes for people with first-episode psychosis ${ }^{1,2}$ and poorer quality of life at first contact with services. ${ }^{1}$ Minimising DUP is a stated aim of early intervention services. ${ }^{3}$ However, long DUP is common: one systematic review found mean DUP of over 2 years; ${ }^{1}$ median DUP of up to 26 weeks has been reported. ${ }^{4}$ Treatment delays can occur both before and after someone has initiated help-seeking and made contact with health services. ${ }^{5}$ Strategies to reduce treatment delay for people with first-episode psychosis are widely advocated as a plausible way in which patient outcomes and experience of services may be enhanced. In the UK, guidelines from the National Institute for Health and Clinical Excellence (NICE) identify one defining responsibility of early intervention services as education of the wider community to reduce obstacles to early engagement in treatment. ${ }^{6}$ Aiming to reduce DUP by increasing the awareness of signs and symptoms of psychosis by professionals and/or the general public has been explicitly advocated by international experts ${ }^{7}$ and recommended for early intervention services in UK government guidance. ${ }^{8,9}$

The terms early detection and early intervention are used to describe both preventive interventions for people at risk of developing psychosis and interventions to provide prompt treatment for people once they have developed psychosis. ${ }^{10}$ This review is concerned only with interventions seeking to reduce treatment delay for people with psychosis. This is a comparatively uncontroversial and more commonly pursued aim for early intervention services, without the potential ethical and cost implications ${ }^{11,12}$ of providing treatment for people identified as at risk of subsequently developing psychosis.

A Cochrane review of early intervention for psychosis ${ }^{13}$ included early detection initiatives for people with first-episode psychosis. However, none of the available evidence was included, mainly owing to the inclusion criterion of randomised studies only. Three other reviews of early intervention include some studies of early detection initiatives. ${ }^{14-16}$ Only one of these, ${ }^{14}$ from 2001, reports a systematic search strategy and none describes and typifies different early detection approaches. In an expanding research field, an up-to-date, fully systematic review of all available evidence regarding early detection initiatives is therefore highly relevant.

\section{Method}

\section{Inclusion criteria}

Interventions

Studies of any intervention designed to enhance the identification and prompt treatment of people with first-episode psychosis were included. The review focused on interventions to reduce delays and facilitate access to treatment: studies evaluating the impact on patient outcomes of early intervention services once patients are in contact, or of specific treatment strategies, were therefore excluded.

\section{Participants}

The review included studies of interventions to promote identification and early access to treatment for people with first-episode psychosis. Studies concerning only populations with at-risk mental states but yet to develop psychosis, or people already being treated for psychosis, were excluded.

\section{Type of study}

Any study comparing an early detection intervention with standard service procedures (in early intervention or other mental health services) was included. These included cluster randomised studies, two-group non-randomised comparison studies and historical comparison studies. Individual randomised controlled trials are not possible in studies of early detection initiatives as individuals cannot be randomly allocated to early detection strategies which, by their nature, target groups in the general population from whom referrals might be obtained. 


\section{Outcomes}

Studies were included which evaluated any of the following outcomes:

(a) DUP of people with first-episode psychosis admitted to services

(b) number of people with first-episode psychosis admitted to services

(c) health status, experience of care or referral pathways of people with first-episode psychosis admitted to services

(d) the referral behaviour of groups targeted in early detection initiatives.

\section{Search strategy}

Four electronic searches were conducted, combining terms for psychosis and DUP or early detection, including filters for randomised controlled trials, observational studies, systematic reviews and grey literature. The searches were conducted across the following electronic databases from inception to May 2009: EMBASE, MEDLINE, PsycINFO, CINAHL and IBSS. Systematic reviews were additionally searched for in the Cochrane Database of Systematic Reviews and the Cochrane Database of Abstracts of Reviews of Effects (DARE) and randomised controlled trials were additionally searched for in the Cochrane Central Trials Register (CENTRAL). Grey literature was additionally searched for in HMIC and PsycEXTRA databases. The search terms used in MEDLINE are provided on p. 4 of the online supplement to this article. Search terms were amended as required for searching other databases.

Grey literature was also sought using the free text and keyword searches of ZETOC, SIGLE, the National Health Service (NHS) National Research Register and UK Clinical Research Network databases. Reference lists from all included studies and relevant reviews were hand searched. Leading national and international research centres and services were contacted by letter or email to try to locate any unpublished data that might exist as a result of previous or ongoing evaluation.

All retrieved articles were imported and screened in Reference Manager. Duplicate articles were removed at the stage of whole article screening. Where studies were multiply reported, one main article was included in the review: where additional information was included in other papers, references were provided in the results section. The final inclusion total from the search thus represents the number of separate studies identified.

Selection of studies for inclusion in the review was made by a single reviewer (M.C. or B.L-E.). A subsample of 20 studies was assessed by a second reviewer (L.H.) to check adherence to inclusion criteria in study selection. Queries about inclusion were resolved through discussion with a third reviewer (S.J.).

\section{Data abstraction}

The following information was collected: study design, characteristics of the early detection intervention, stated outcomes, measures and results from the study.

Two domains were used to categorise early detection initiatives described in included studies: target group (whose behaviour the intervention was designed to influence) and medium of intervention. The primary target group was categorised as one or more of:

(a) mental health service providers

(b) other health professionals (e.g. general practitioners (GPs)) (c) workers in non-health community organisations (e.g. teachers, youth workers, faith group leaders, housing workers)

(d) a specific group of potential service users (e.g. school or college students)

(e) multifocus: more than one of the above groups or the general population.

The primary medium of intervention was categorised as one or more of: written or audio-visual information (printed material, television, radio, video, web-based); direct contact (individual or group education or training); or service configuration (changes in the organisation of mental health services such as the establishment of an early intervention service). Categorisation was undertaken separately by two reviewers (B.L-E. and L.H.): any disagreement was resolved by discussion or with reference to a third reviewer (S.J.).

Study quality was assessed using an assessment measure developed by Thomas. ${ }^{17}$ The measure allows studies to be rated as strong, moderate or weak in six key domains affecting study quality: selection bias, allocation bias, masking, confounders, data collection methods and withdrawals (before or during treatment). Criteria for assessing data collection methods were operationalised as follows: studies assessing DUP rated strong if DUP was defined and a published assessment tool was used in collecting DUP data; studies rated moderate if one of these criteria was met and weak if neither was met. For this review, no rating was made for two domains - masking and measurement of confounders. Given the public nature of early detection campaigns and the in-depth information about pathways through services required for DUP measurement, masking of participants or raters is not possible. The unit of comparison for early detection initiatives is areas (e.g. GP practice areas or regions) rather than individuals. There is no clear basis for deciding in advance which area characteristic should be measured. For studies of multifocus initiatives involving two or a few large areas, it is not evident how measured differences could be accounted for in analyses. For quality domains where ratings of quality were not made, relevant features of study design or recruitment were described.

\section{Reporting of results}

Results for all review outcomes were reported from all included studies. Mean and median DUP from studies are reported where possible. $P$-values are reported for all significant results from included studies. Assessment method and definition of DUP used by included studies are described in the data supplement. A narrative synthesis of included studies is presented.

\section{Results}

\section{Study selection}

The literature search found 11 studies for inclusion in the review. Study selection is presented in a flow diagram in Fig. 1.

The 11 included studies evaluated 8 early detection initiatives. (Three different evaluations of one initiative, the Scandinavian TIPS Programme $e^{18-20}$ and two evaluations of one initiative at the Australian EPPIC service ${ }^{21,22}$ were conducted.) Outcomes for number of referrals or DUP were reported from seven of the eight initiatives: in the Irish DETECT initiative, ${ }^{23}$ only the impact on referrers' behaviour was reported.

Excluded studies comprised studies not concerning early detection initiatives, descriptive reports not evaluating early detection initiatives, review articles, secondary reports of included studies and duplicates. Two studies of some relevance were excluded from this review because they lacked any comparison 


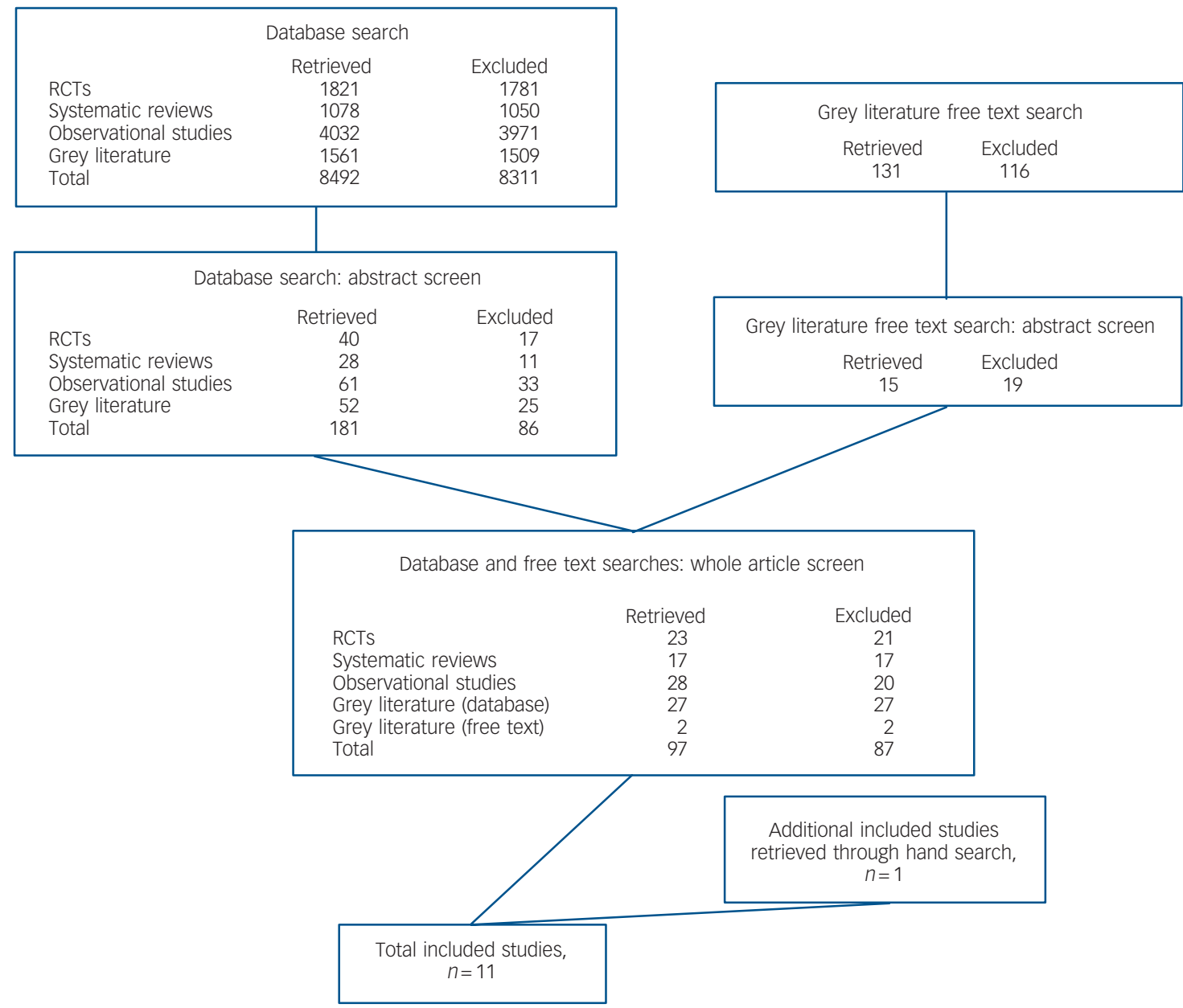

Fig. 1 Early detection literature search flow diagram. RCTs, randomised controlled trials.

group. Evaluations of the OPUS Project in Denmark ${ }^{24}$ and the PEPP service in Canada ${ }^{25}$ assessed DUP and numbers of referrals at newly established early intervention services over the first 3 years of their operation. Findings from these two studies are discussed.

\section{Types of early detection initiative}

Details of the eight early detection initiatives evaluated by studies included in this review are provided in Table 1.

Three initiatives involved GP education campaigns. Two UK studies, REDIRECT ${ }^{26}$ and LEOCAT, ${ }^{27}$ provided an educational workshop to GP practices and follow-up contact. The workshop involved a video presentation, oral information and distribution of leaflets about early signs of psychosis and where to refer. An Irish study, DETECT, ${ }^{23}$ sent information packs to all GPs within the study area and conducted workshops for large groups of GPs. All three GP education initiatives focused on improving GPs' awareness of the signs and symptoms of early psychosis and encouraging prompt referral to early intervention services. One initiative involved service configuration: two of the included studies $^{21,22}$ evaluated the newly established EPPIC service in Australia, which was a dedicated service for people with firstepisode psychosis and sought to provide a clear point of referral and swift service response. The establishment of this service was reported as accompanied by some advertising to health professionals and other community organisations, but these activities were briefly described and appear to have been small-scale and informal in comparison to initiatives categorised as multifocus.

Four initiatives linked to local early intervention services were multifocus. The TIPS Project in Norway ${ }^{18-20}$ was the most extensive, running for 4 years in two healthcare sectors. It provided face-to-face training for GPs and other health professionals and visits twice a term to every school in the study area, providing information to teachers, counsellors and pupils. Help-seeking and knowledge about psychosis were promoted to the general public through information distributed directly to households and advertising and information in mainstream media. The campaign's primary message concerned the benefits of early treatment, but materials were also designed to present a non-frightening, non-stigmatising image of psychosis and mental health services.

The EPIP Project in Singapore ${ }^{28}$ similarly contacted healthcare providers and schools and used mainstream media to engage the general public. Interventions included a docudrama on primetime television in four languages, advertising on television, radio and newspapers, use of celebrities in media campaigns, public poster and postcard campaigns and the establishment of a telephone hotline for the public to contact for advice or help.

The initiative at the PEPP service in $\mathrm{Canada}^{29}$ provided written and telephone contact to GPs, visits to school counsellors' meetings and a public awareness campaign, using posters and distribution of leaflets and other materials in public places and a $30 \mathrm{~s}$ television and cinema advertisement. The campaign focused specifically on enhancing awareness of signs of early psychosis, the benefits of early treatment and how to contact PEPP. Attempts to 


\begin{tabular}{|c|c|c|c|c|c|}
\hline Initiative & Location & $\begin{array}{l}\text { Duration } \\
\text { of initiative }\end{array}$ & $\begin{array}{l}\text { Target } \\
\text { groups }\end{array}$ & $\begin{array}{l}\text { Primary } \\
\text { media }\end{array}$ & Description \\
\hline LEOCAT $^{27}$ & London, UK & $\begin{array}{l}27 \text { months, } \\
2003-2005\end{array}$ & GPS & Direct contact & $\begin{array}{l}\text { Workshop involving } 10 \text { min video and } 15 \text { min presentation provided } \\
\text { to GP practices. Informal follow-up offered. }\end{array}$ \\
\hline REDIRECT ${ }^{26}$ & $\begin{array}{l}\text { Birmingham, } \\
\text { UK }\end{array}$ & $\begin{array}{l}30 \text { months, } \\
2003-2006\end{array}$ & GPS & Direct contact & $\begin{array}{l}\text { Workshop involving } 17 \text { min video and } 15 \text { min Q\&A session provided } \\
\text { to GP practices. Refresher session } 6 \text { months later with video. }\end{array}$ \\
\hline DETECT $^{23}$ & Dublin, Ireland & $\begin{array}{l}20 \text { months, } \\
2005-2007\end{array}$ & GPS & $\begin{array}{l}\text { Written or audio- } \\
\text { visual information } \\
\text { Direct contact }\end{array}$ & $\begin{array}{l}\text { Information pack about early intervention service and signs and } \\
\text { symptoms provided to all GPS. } 45 \text { min workshop involving presenting } \\
\text { information, Q\&A and case vignettes delivered to groups of GPS. }\end{array}$ \\
\hline EPPIC $1^{21,22}$ & $\begin{array}{l}\text { Melbourne, } \\
\text { Australia }\end{array}$ & $\begin{array}{l}8 \text { months, } \\
1993\end{array}$ & $\begin{array}{l}\text { Service } \\
\text { providers }\end{array}$ & $\begin{array}{l}\text { Service } \\
\text { configuration }\end{array}$ & $\begin{array}{l}\text { An early intervention team (EPPIC) was established. Unspecified } \\
\text { networking and community education activities also undertaken }\end{array}$ \\
\hline TIPS $^{18-20}$ & $\begin{array}{l}\text { Rogaland } \\
\text { County, } \\
\text { Norway }\end{array}$ & $\begin{array}{l}4 \text { years, } \\
1997-2000\end{array}$ & Multifocus & $\begin{array}{l}\text { Written or audio- } \\
\text { visual information } \\
\text { Direct contact } \\
\text { Service } \\
\text { configuration }\end{array}$ & $\begin{array}{l}\text { Early intervention teams established. Brochure delivered to } 110000 \\
\text { households. Newspaper, radio, television and cinema advertising } \\
\text { campaign. Leaflet distribution. } \\
\text { Visits twice a term to schools, education about symptoms and how } \\
\text { to contact services to teachers and pupils. } \\
\text { Three- to four-hour training seminar to health professionals and } \\
\text { 6-monthly follow-up letter to GPS. }\end{array}$ \\
\hline EPPIC $2^{30}$ & $\begin{array}{l}\text { Melbourne, } \\
\text { Australia }\end{array}$ & $\begin{array}{l}12 \text { months, } \\
1996-1997\end{array}$ & Multifocus & $\begin{array}{l}\text { Written or audio- } \\
\text { visual information } \\
\text { Direct contact }\end{array}$ & $\begin{array}{l}\text { Mobile assessment team established. } 12 \text { educational sessions } \\
\text { delivered to staff and pupils in } 6 \text { schools, promoting help-seeking } \\
\text { and describing signs and symptoms. Video sent to } 300 \text { GPS. Mail out } \\
\text { every } 6 \text { months. Three workshops run with } 90 \text { GPs with education } \\
\text { about psychosis. Similar links made with school counsellors and } \\
\text { youth workers. }\end{array}$ \\
\hline PEPP $^{29}$ & $\begin{array}{l}\text { Ontario, } \\
\text { Canada }\end{array}$ & $\begin{array}{l}2 \text { years, } \\
2002-2004\end{array}$ & Multifocus & $\begin{array}{l}\text { Written or audio- } \\
\text { visual information } \\
\text { Direct contact }\end{array}$ & $\begin{array}{l}\text { Public poster and leaflet campaign. Film shown on television and } \\
\text { university campus cinemas. PEPP clinicians attended schools } \\
\text { counselling meetings monthly. Pamphlets sent and telephone } \\
\text { contact made with GPS. }\end{array}$ \\
\hline $\mathrm{EPIP}^{28}$ & Singapore & $\begin{array}{l}2 \text { years, } \\
2001-2003\end{array}$ & Multifocus & $\begin{array}{l}\text { Written or audio- } \\
\text { visual information } \\
\text { Direct contact } \\
\text { Service } \\
\text { configuration }\end{array}$ & $\begin{array}{l}\text { Radio, newspaper and poster advertising, mass postcard distribution, } \\
\text { television docudrama and radio features about psychosis, celebrity } \\
\text { endorsement of campaign, public forums. Website and telephone } \\
\text { hotline set up. Bi-monthly newsletter distributed to GPS and school } \\
\text { counsellors and talks and workshops conducted with primary health } \\
\text { professionals. }\end{array}$ \\
\hline
\end{tabular}

GPS, general practitioners; Q\&A, question and answer.

address negative attitudes to psychosis or mental health services among the general population were not described. ${ }^{29}$

The EPPIC initiative ${ }^{30}$ provided face-to-face training to GPs, youth workers and counsellors, aiming to enhance recognition and awareness of symptoms of early psychosis. The initiative also sought to promote help-seeking by young people and their families by providing 12 presentations in 6 schools within the catchment areas. The authors acknowledge that budgetary restrictions limited the EPPIC initiative in terms of promoting help-seeking. ${ }^{30}$

\section{Study design and quality}

The characteristics of included studies are reported in online Table DS1.

The 11 included studies comprised two cluster randomised trials, two prospective two-group natural experiments and seven studies which retrospectively compared two groups or one group with a historical comparison. The two cluster randomised trials evaluated GP education initiatives. The two non-randomised prospective studies ${ }^{19,30}$ evaluated multifocus campaigns. All studies evaluating the impact of service configuration used retrospective study designs. Duration of untreated psychosis was the most commonly assessed outcome, measured by ten studies.

The quality of studies included in the review was compromised by several factors. All nine non-randomised studies either did not measure any differences or were unable to adjust in analyses for measured differences between the intervention and comparison areas. Only 4 of the 11 studies were prospective evaluations. Only six of ten studies which measured DUP obtained data from an adequate number (defined as over $60 \%)^{17}$ of eligible patients. Two studies did not report how DUP (onset of psychosis and start of treatment) was defined. Of the ten studies which measured DUP, six did not report using a published assessment tool to elicit information about DUP. Overall, only two studies ${ }^{19,30}$ were prospective evaluations, based comparisons of DUP on data from a reported, adequate proportion of all eligible patients and clearly defined how DUP was measured. One study ${ }^{26}$ obtained complete data for numbers of referrals from a robustly designed cluster randomised study. Full description of the quality assessment of studies included in this review is provided in online Table DS2.

\section{Study results}

Results from included studies regarding DUP and numbers of referrals are presented in online Table DS3.

Significant reductions in mean or median DUP were reported for two out of four multifocus campaigns - from all evaluations of the Norwegian TIPS Project $(P=0.005, P=0.003, P<0.005)^{18-20}$ and the EPIP Project in Singapore $(P=0.002) .{ }^{28}$ Two multifocus campaigns, at the EPPIC service in Australia ${ }^{30}$ and the PEPP service in Canada, ${ }^{29}$ found no significant difference in DUP in the campaign and comparison areas. No studies evaluating GP education campaigns or changes in service configuration found 
a significant reduction in mean or median DUP from the early detection initiative.

No study found clear evidence of an increase in the number of people with first-episode psychosis referred to services following an early detection initiative. REDIRECT, ${ }^{26}$ a cluster randomised trial of a GP education programme, found no significant difference in the number of referrals from GP practices in the intervention and control groups. The large-scale, multifocus interventions conducted by the TIPS Project ${ }^{19}$ and PEPP service ${ }^{29}$ reported similar incidence rates of treated cases of first-episode psychosis in regions exposed to the campaigns and comparison areas (TIPS: intervention, 50:100000 v. control, 66:100 000; PEPP: intervention, 27.5: $100000 v$. control 26:100 000).

Other outcomes measured by included studies were patients' pathways to care and their health status at admission and referrers' behaviour. Four studies evaluated pathways to care. For one GP education initiative, REDIRECT, ${ }^{26}$ and one mass campaign at the PEPP service, ${ }^{29}$ no significant difference with comparison groups was found in referral source. However, one UK GP education initiative, the LEOCAT study, ${ }^{27}$ found that patients from GP practices receiving the intervention were less likely to have contact with Accident and Emergency (A\&E) departments in their pathway to mental health services. One multifocus initiative, the EPIP Project in Singapore, ${ }^{28}$ found during the campaign that patients were significantly more likely to self-refer and less likely to be referred via the police than in the historical comparison period.

Five studies measured the severity of illness of patients with first-episode psychosis at first service contact. Patients from areas exposed to a multifocus intervention were found to have significantly less severe symptoms than those from comparison groups in the TIPS Project ${ }^{19,20}$ and the EPPIC service. ${ }^{30}$ No significant difference in patients' symptom severity was found between intervention and comparison areas in the PEPP service however. ${ }^{29}$ The REDIRECT study ${ }^{26}$ found no significant difference in symptom severity or premorbid adjustment between patients admitted from areas included in a GP education campaign and comparison areas.

All three studies of GP education initiatives included in this review found some evidence of impact of the initiative on GPs' referral behaviour. DETECT ${ }^{23}$ and LEOCAT $^{27}$ found that GPs receiving education were more likely to refer people with first-episode psychosis to mental health services than GPs in a comparison group. REDIRECT ${ }^{26}$ found that the time from patients' first contact with GPs to referral to early intervention services was significantly shorter in duration for patients from GP surgeries in the intervention arm of the study.

\section{Discussion}

\section{Understanding the results}

Two negative findings regarding early detection strategies are suggested by current evidence. First, two randomised studies ${ }^{26,27}$ suggest that educating GPs about psychosis and referral procedures may have some impact on service delays once help-seeking has been initiated - and therefore could form a useful part of a broader initiative to reduce DUP - but by itself is insufficient to significantly affect overall DUP or numbers of referrals of people with first-episode psychosis. Second, establishing early intervention services probably does not on its own reduce DUP. The apparently shorter DUP found at the EPPIC early intervention service compared with standard services by Yung and colleagues ${ }^{22}$ was not assessed for statistical significance and was not replicated by a more robust evaluation of the same EPPIC service. ${ }^{21}$ Negative conclusions regarding the impact of service configuration on its own are corroborated by the finding from the TIPS study, ${ }^{20}$ where the positive impact on DUP of establishing an early intervention service at the same time as running a public awareness campaign dissipated once the awareness campaign was discontinued. Two studies excluded from this review ${ }^{24,25}$ also did not find any reduction in DUP or increase in referral numbers over the first 3 years of an early intervention service's operation.

Evidence regarding the components of DUP may explain these negative findings. About half of DUP may occur before any helpseeking from health services is initiated. ${ }^{5,27}$ Changing service configuration or educating health professionals can only affect how promptly treatment is provided once someone with firstepisode psychosis has come to health services' attention. Early detection strategies which limit their focus to reducing service delay may be insufficient to significantly influence DUP as a whole. An additional focus on enhancing help-seeking behaviour by people with developing psychosis or those already in contact with them may be required.

The evidence regarding the effectiveness for early detection of multifocus campaigns is more equivocal. The Norwegian TIPS ${ }^{18-20}$ and Singapore EPIP $^{28}$ initiatives showed a positive impact in reducing DUP, while the multifocus campaigns at the Australian EPPIC $^{30}$ and Canadian PEPP $^{29}$ services did not. Differences in baseline DUP do not help explain the disparity in outcomes. The TIPS campaign was successful in reducing DUP despite a median DUP in the comparison area of 16 weeks, ${ }^{19}$ which was comparable to that in the EPPIC study $(15 \text { weeks })^{30}$ and briefer than that in the PEPP study (22 weeks). ${ }^{29}$ Positive findings do not simply reflect that it is easier to reduce DUP in areas where it is lengthy to begin with.

Krstev and colleagues ${ }^{30}$ note the (non-significantly) shorter median DUP in the mass campaign area of their study and the significantly greater incidence of patients with a very long DUP of over 3 years in the intervention area. They suggest that the EPPIC mass campaign's negative results regarding DUP may in part reflect the campaign's identification of a number of patients with long DUP who would otherwise never have come into treatment. This is unproven, however, and not supported by the comparable incidence rates for treated cases in intervention and comparison areas reported by the TIPS ${ }^{19}$ and PEPP $^{29}$ studies.

Variation in outcomes for DUP following multifocus campaigns may be explained by the content and intensity of the different campaigns. Compared with the unsuccessful $\mathrm{PEPP}^{29}$ and EPPIC $^{30}$ early detection initiatives, the successful TIPS ${ }^{19}$ and EPIP $^{28}$ projects were characterised by: greater overall intensity; more use of mainstream media; greater targeting of the general public in addition to groups of professionals; and more emphasis on promoting help-seeking and changing attitudes to psychosis, not just increasing knowledge about symptoms and services. In order to achieve significant reductions in DUP, multifocus campaigns may require vigorous targeting of barriers to initiating help-seeking as well as reduction in service delays. The conclusion that changing public attitudes and behaviour regarding psychosis may require high-intensity initiatives has some support from wider mental health promotion literature. The Mental Health First Aid initiative developed in Australia has reported greater success in changing beliefs about treatment for and social distance from people with mental illness generally than schizophrenia in particular. $^{31}$ A 3-year German anti-stigma campaign reported only a small positive impact on public attitudes to psychosis. ${ }^{32} \mathrm{~A}$ review of mental health anti-stigma campaigns concluded that changes in attitudes may be modest and hard to sustain and that campaigns including education and contact with a person with mental illness are more effective than education alone. ${ }^{33}$ 


\section{Limitations}

This review reflects knowledge about initiatives to shorten DUP now that a first generation of studies prompted by the development of early intervention aims and services have reported. However, the strength of current evidence is limited by the modest number of relevant studies, variation in the nature of early detection initiatives and comparison services and the quality of studies. Evaluation of early detection campaigns, where the unit of comparison is services or catchment areas rather than individuals, is inherently problematic. Considerable practical difficulties exist in recruiting sufficient numbers of large areas for cluster randomisation, ensuring that campaigns reach only intervention areas - thus avoiding cross-contamination - and in adjusting for confounding differences between intervention and comparison areas. Conclusions about the effectiveness of early detection campaigns can therefore only be provisional.

Three limitations to the appraisal of studies by this review concern: the descriptive typology of early detection initiatives; the quality assessment of included studies; and the synthesis of study results.

Campbell et al describe types of complex intervention to improve health. ${ }^{34}$ Green and colleagues distinguish modes of delivery of health education, describing communication of information, interactive training and organisational development. ${ }^{35}$ These descriptions were used, in the absence of an established typology, to inform the development of two domains used to categorise early detection initiatives in this review. However, these broad descriptive categories may fail to distinguish important differences between interventions.

Given the very limited evidence base, all types of study evaluating early detection initiatives were included in this review to avoid ignoring available evidence. The quality assessment measure used in this review ${ }^{17}$ was recommended in a review of quality assessment measures ${ }^{36}$ as suitable to use with randomised and non-randomised studies. Important factors affecting study quality are described in this review and used to consider the strength of available evidence. However, the basis on which to do this is imprecise and studies of higher and lower quality overall are not systematically distinguished.

Meta-analysis of data from different studies was precluded by the nature of reported DUP data (skewed mean DUP data or median DUP lacking information about variance). Meta-analysis may anyway have been inappropriate for the studies in this review. Its implied precision about effect sizes and confidence intervals would have been misleading because of: the moderate quality of included studies; variation between studies in how a key outcome - DUP - was defined and the validity of DUP measures; and the substantial heterogeneity between studies in the nature of comparison standard services and the content of early detection interventions. The review's narrative synthesis of available evidence does reveal gaps in knowledge and indicate the direction and strength of current evidence and, by comparing successful and unsuccessful interventions, helps consideration of the mechanisms which may influence the effectiveness of early detection initiatives.

\section{Research implications}

More good-quality studies are needed for all types of early detection initiatives to strengthen the limited current evidence base. Cluster randomised studies are desirable where possible. Future studies should at least be prospective. A consensus is also desirable about how to measure DUP. Recommendations for DUP measurement ${ }^{37}$ - for studies to use a standardised assessment measure, to base ratings on multiple informants and to assess reliability of raters' measurements - have not been consistently adhered to by studies included in this review. Direct comparison of results from studies in this review is hampered by variation in exactly what was being measured and how. (Description of DUP measurement methods used is provided in online Table DS4.) Early intervention services have been relatively successful in implementing routine data collection, for example both in the UK through the MiData Project ${ }^{38}$ and in New Zealand. ${ }^{39}$ Robust, routine collection of data regarding DUP, pathways to care and other baseline information for people with first-episode psychosis may make it substantially easier to carry out large-scale evaluations of initiatives at catchment area, regional or even national levels.

There is a particular need for studies in three areas relevant to early detection where there is a lack of current evidence. First, no studies found by this review described youth-focused initiatives (e.g. targeting pupils at schools, colleges and universities, including using youth-focused media such as advertising on social-networking sites). Second, no studies evaluated initiatives directed primarily at non-health community professionals (e.g. teachers, school counsellors, youth workers, housing or employment service staff, cultural or faith group organisers). Initiatives targeting young people or non-health service professionals might enhance help-seeking behaviour and, by encouraging direct contact with early intervention services, could also reduce service delays. Both approaches therefore merit investigation. Third, although evidence suggests that establishing dedicated services for people with first-episode psychosis does not by itself reduce DUP, the impact on DUP of services for people with prodromal or at-risk mental states is unclear. Services which aim to prevent transition to psychosis, when they fail in their primary aim, might still fulfil a useful function in ensuring that prompt treatment is delivered once psychosis begins. However, evaluation of psychosis prevention services for people with at-risk mental states has concentrated on outcomes (beyond the scope of this review) for these individuals and their rates of transition to psychosis. We found no studies which evaluated the impact of a psychosis prevention service on mean or median DUP for people with first-episode psychosis across a whole geographical population.

In addition to assessment of the impact of initiatives on number of referrals and length of DUP, early detection campaigns could be informed by a focus on three other key areas by future studies.

First, attention should be paid to the components of DUP as well as its overall duration. The REDIRECT study ${ }^{26}$ in Birmingham, UK, for example, produced apparently contradictory findings that a GP education initiative prompted swifter referrals of people with first-episode psychosis to mental health services by GPs but had no significant effect on patients' overall DUP. Not all patients in the study consulted their GP during their pathway to care; an examination by Brunet and colleagues of the components of DUP for patients in the local service system ${ }^{40}$ also helps explain this finding. Delays within primary care formed only a small proportion of overall DUP, considerably less than delays both in initial help-seeking and within mental health services. This suggests that, in Birmingham, primary care was not a promising target for an intervention to reduce DUP among people with first-episode psychosis. Brunet et al also found that mental health service delays comprised several distinct components, each of which might require a different approach. These included transfers between services (community mental health teams (CMHTs) to early intervention), waiting times for an initial appointment and subsequent delays in achieving treatment with antipsychotic medication. ${ }^{40}$ The components of DUP are likely to vary across different areas, countries or service configurations. 
If the important components of DUP within a target area are understood, local early detection initiatives can be planned accordingly for maximum effect.

Second, outlying cases are important in consideration of DUP. In this review, studies typically found a substantially longer mean DUP than median DUP, with the mean inflated by a small number of cases with very long DUP of several years. A number of studies found that even in the comparison services, median DUP was less than $^{21,26}$ or close to ${ }^{19,30}$ the World Health Organization's 3-month target for median DUP. ${ }^{3}$ Some early detection campaigns also reported identifying more patients with very long DUP, some of whom may not have come to the attention of standard services. ${ }^{29,30}$ Improving access to treatment for the small group of people with first-episode psychosis who take a very long time to reach services, and whose long DUP suggests a poor prognosis, seems an important aim for services. In some areas, this may be a higher priority than achieving further reductions in an already modest median DUP. Greater understanding of the characteristics of people with long DUP and how they are eventually initiated into treatment could inform interventions specifically to achieve this aim.

Third, future evaluations of any type of early detection initiative should assess patients' pathways to care and experience of initial service contact. Even if early detection initiatives have no effect on the number of referrals or DUP, they might reduce costs or increase patient satisfaction if they lead to reduced contact with police, $A \& E$ and in-patient services during pathways to care. Because early experiences of mental health services may have enduring influence on engagement, providing an initial contact with services which is acceptable to patients is of particular importance. Current evidence is insufficient to establish whether early detection initiatives have any such effect.

\section{Clinical implications}

Studies in this review found that service delays in providing appropriate treatment for people with first-episode psychosis can be considerable, within mental health services as well as between primary and secondary care. The REDIRECT study in the UK, for example, found substantial inconsistency in care pathways for people with first-episode psychosis following referral to mental health services: over $30 \%(54 / 179)$ of eligible patients in the study were not referred promptly to the local dedicated firstepisode psychosis services by CMHTs. ${ }^{26}$ Minimising mental health service delays and barriers to effective treatment is an important goal for mental health services but is probably insufficient to reduce DUP significantly.

Despite strong recommendations in policy guidance that service planners and managers attend to early detection and prompt treatment provision for people with first-episode psychosis, ${ }^{8,9}$ what else they should be doing to facilitate this is unclear from current evidence. General practitioner education campaigns appear by themselves to be ineffective. Campaigns targeting community professionals or young people are of interest and potential value; such initiatives lack current evidence of effectiveness, however, and should therefore be accompanied by rigorous evaluation.

Current evidence suggests that intensive, large-scale multifocus initiatives including public awareness campaigns are the most promising means to enhance early detection of psychosis. However, knowledge is limited about optimal content and media for such initiatives in mental health settings. Many of the factors which predict active help-seeking in mental health are not easily amenable to change. Being female and experiencing severe psychological distress have been identified as the strongest predictors of help-seeking for emotional problems. ${ }^{41}$ An empirically based model of help-seeking identified some people as predisposed to self-concealment (keeping personally distressing information from others) and less likely than others to seek help. ${ }^{42}$ More promisingly, contact with someone with a mental health problem who has sought professional help has been found to be influential in reducing stigma ${ }^{43}$ and encouraging help-seeking for emotional problems. ${ }^{42}$ The conclusion of a study of stigma campaigns, ${ }^{43}$ that the stories and experiences of people who live with mental health problems should be to the fore, may also apply to early detection campaigns. Prominent service user involvement may be needed.

Findings from general medicine may also usefully inform the content of early detection initiatives for psychosis. Other areas of health associated with stigma and with a youthful target population, such as smoking and sexual behaviour, also suggest that intensive, multicomponent awareness campaigns may be most effective. ${ }^{44-46}$ In the light of mixed evidence regarding the effectiveness of initiatives to reduce treatment delay for heart attack, ${ }^{47}$ Turner compared successful and unsuccessful initiatives. ${ }^{48}$ Features of successful campaigns with potential relevance for psychosis were that: they involved a full range of media; they included accurate portrayal of a comprehensive set of early symptoms - not just the most common ones; and they advised assertively going to seek help if response to a telephone call was not immediate. A review of initiatives to promote early presentation for cancer suggests that initiatives targeting individuals who are at risk, as well as whole-community interventions, may be effective. ${ }^{49}$

Whatever their content, large initiatives involving public awareness campaigns cannot easily be planned and run by individual services or local service planners. They may be more efficient and effective with organisational leadership and resources from regional or NHS planners. This presents a challenge for macro-level mental health service delivery and organisation if the goal of early intervention for psychosis is to be fully realised.

\section{Brynmor Lloyd-Evans, PhD, Department of Mental Health Sciences, University College London, and Early Intervention Service, Camden and Islington NHS \\ Foundation Trust; Michelle crosby, BSc, Early Intervention Service, Camden and Islington NHS Foundation Trust; Sarah Stockton, PhD, Department of Psychiatry, University of Oxford; Stephen Pilling, PhD, Centre for Outcomes Research and Effectiveness (CORE), University College London; Lorna Hobbs, BSc, Early Intervention Service, Camden and Islington NHS Foundation Trust, and Centre for Outcomes Research and Effectiveness (CORE), University College London; \\ Mark Hinton, MSC, Early Intervention Service, Camden and Islington NHS Foundation Trust; Sonia Johnson, MD, Department of Mental Health Sciences, University College London, and Early Intervention Service, Camden and Islington NHS Foundation Trust, London, UK}

Correspondence: Brynmor Lloyd-Evans, Department of Mental Health Sciences, University College London, Charles Bell House, 67-73 Riding House Street, London W1W 7EJ, UK. Email: b.Iloyd-evans@ucl.ac.uk

First received 13 Nov 2009, final revision 28 Sep 2010, accepted 6 Oct 2010

\section{Acknowledgements}

This paper presents independent research work commissioned by the National Institute for Health Research (NIHR) under its Research for Patient Benefit (RfPB) Programme (PB-PG-0706-10230). The views expressed are those of the authors and not necessarily those of the National Health Service, the NIHR or the Department of Health.

\section{References}

1 Marshall M, Lewis S, Lockwood A, Drake R, Jones P, Croudace T. Assocaition between duration of untreated psychosis and outcome in cohorts of firstepisode patients. Arch Gen Psychiatry 2005; 62: 975-83.

2 Perkins D, Gu H, Boteva K, Lieberman J. Relationship between duration of untreated psychosis and outcome in first episode schizophrenia: a critical review and meta-analysis. Am J Psychiatry 2005; 162: 1785-804. 
3 Bertolote J, McGorry P. Early intervention and recovery for young people with psychosis: consensus statement. Br J Psychiatry 2005; 187 (suppl 48): 116-9.

4 Norman R, Malla A, Verdi M, Hassall L, Fazekas C. Understanding delay in treatment for first-episode psychosis. Psychol Med 2006; 34: 255-66.

5 Malla A, Bechard-Evans L, Joober R, King S, Abadi S. Understanding the complexities of delay in treatment of psychosis and relevance for early detection interventions. Schizophr Res 2006; 86 (suppl 1): S40.

6 National Collaborating Centre for Mental Health. Schizophrenia: Core Interventions in the Treatment and Management of Schizophrenia in Primary and Secondary Care (Update). Clinical Guideline CG82. National Institute for Health and Clinical Excellence, 2009.

7 International Early Psychosis Association Writing Group. International clinical practice guidelines for early psychosis. Br J Psychiatry 2005; 187 (suppl 48): s120-4.

8 Department of Health. Mental Health Policy Implementation Guide. Department of Health, 2001.

9 Care Services Improvement Partnership. Report on Early Detection and Intervention for Young People at Risk of Developing Psychosis. CSIP, 2005.

10 Warner R. Problems with early and very early intervention in psychosis. $\mathrm{Br} J$ Psychiatry 2005; 187 (suppl 48): s104-7.

11 McGlashan T, Miller T, Woods S. Pre-onset detection and intervention research in schizophrenia psychoses: current estimates of benefit and risk. Schizophr Bull 2001; 27: 563-70.

12 Bentall R, Morrison A. More harm than good: the case against using antipsychotic drugs to prevent severe mental illness. J Ment Health 2002; 11: 351-6.

13 Marshall M, Rathbone J. Early intervention for psychosis. Cochrane Database Syst Rev 2006; 4: CD004718.

14 Larsen T, Friis S, Haahr U, Joa I, Johannessen J, Melle I, et al. Early detection and intervention in first episode schizophrenia: a critical review. Acta Psychiatr Scand 2001; 103: 323-34.

15 Malla A, Norman R, Joober R. First-episode psychosis, early intervention and outcome: what have we learned? Can J Psychiatry 2005; 50: 881-91.

16 McGorry P, Killackey E, Yung A. Early intervention in psychotic disorders: detection and treatment of the first episode and the critical early stages. Med J Aust 2007; 187: S8-10.

17 Thomas H. Quality Assessment Tool for Quantitative Studies. Effective Public Health Practice Project. McMaster University, 2003

18 Johannessen J, McGlashan T, Larsen T, Horneland M, Joa I, Mardal S, et al. Early detection strategies for untreated first-episode psychosis. Schizophr Res 2001; 51: 39-46.

19 Melle I, Larsen T, Haahr U, Friis S, Johannessen J, Opjordsmoen S, et al. Reducing the duration of untreated first-episode psychosis. Arch Gen Psychiatry 2004; 61: 143-50.

20 Joa I, Johannessen J, Auestad B, Friis S, McGlashan T, Melle I, et al. The key to reducing duration of untreated psychosis: information campaigns. Schizophr Bull 2008; 34: 466-72.

21 McGorry P, Edwards J, Mihalopoulos C, Harrigan S, Jackson H. EPPIC: an evolving system of early detection and optimal management. Schizophr Bull 1996; 22: 305-26.

22 Yung A, Organ B, Harris M. Management of early psychosis in a generic adult mental health service. Aust N Z J Psychiatry 2003; 37: 429-36.

23 Renwick L, Gavin B, McGlade N, Lacey P, Goggins R, Jackson D, et al. Early intervention service for psychosis: views from primary care. Early Interv Psychiatry 2008; 2: 285-90.

24 Nordentoft M, Thorup A, Petersen L, Ohlenschlaeger J, Ostergaard Christensen T, Krarup G, et al. Does a detection team shorten duration of untreated psychosis? Early Interv Psychiatry 2008; 2: 22-6.

25 Scholten D, Malla A, Norman R, McLean T, Mcintosh E, McDonald C, et al. Removing barriers to treatment of first episode psychoic disorders. Can J Psychiatry 2003; 48: 561-5.

26 Lester H, Birchwood M, Freemantle N, Michail M, Tait L. REDIRECT: cluster randomised controlled trial of GP training in first-episode psychosis. $\mathrm{Br} J \mathrm{Gen}$ Prac 2009; 59: e183-90.

27 Power P, lacoponi E, Reynolds N, Fisher H, Russell M, Garety PA, et al. The Lambeth Early Onset Crisis Assessment Team Study: general practitioner education and access to an early detection team in first-episode psychosis. Br J Psychiatry 2007; 191 (suppl 51): s133-9.

28 Chong S, Mythily S, verma S. Reducing the duration of untreated psychosis and changing help-seeking behaviour in Singapore. Soc Psychiatry Psychiatr Epidemiol 2005; 40: 619-21.

29 Malla A, Norman R, Scholten D, Manchanda R, McLean T. A community intervention for early identification of first-episode psychosis: impact on duration of untreated psychosis (DUP) and patient characteristics. SOC Psychiatry Psychiatr Epidemiol 2005; 40: 337-44

30 Krstev H, Carbone S, Harrigan S, Curry C, Elkins K, McGorry P. Early Intervention in first-episode psychosis: the impact of a community development campaign. Soc Psychiatry Psychiatr Epidemiol 2004; 39: 711-9.

31 Kitchener B, Jorm A. Mental health first aid training in a workplace setting: a randomised controlled trial. BMC Psychiatry 2004; 4: 23.

32 Gaebel W, Zaske H, Baumann A, Klosterkotter J, Maier W, Decker P, et al. Evaluation of the German WPA program against stigma and discrimination because of schizophrenia - open the doors: results from representative telephone surveys before and after three years of anti stigma interventions. Schizophr Res 2008; 98: 184-93.

33 Holzinger A, Dietrich S, Heitmann S, Angermeyer M. Evaluation of targetgroup oriented interventions aimed at reducing the stigma surround mental illness: a systematic review. Psychiatr Prax 2008; 35: 376-86.

34 Campbell M, Fitzpatrick R, Haines A, Kinmouth A, Sandercock $P$, Spiegelhalter $\mathrm{D}$, et al. Framework for design and evaluation of complex interventions to improve health. BMJ 2000; 321: 694-6.

35 Green L, Kreuter M, Deeds S, Partridge K. Health Education Planning: A Diagnostic Approach. Mayfield Publishing, 1980.

36 Deeks J, Dinnes J, D'Amico J, Sowden A, Sakarovitch C, Song F, et al. Evaluating non randomised intervention studies. Health Technol Assess 2003; 7: 1-186.

37 Compton $\mathrm{N}$, Carter $\mathrm{T}$, Bergner $\mathrm{E}$, Franz $\mathrm{L}$, Stewart $\mathrm{T}$, Trotman $\mathrm{H}$, et al. Defining, operationalising and measuring the duration of untreated psychosis: advances, limitations and future directions. Early Interv Psychiatry 2007; 1: 236-50.

38 Fisher $\mathrm{H}$, Theodore $\mathrm{K}$, Power $\mathrm{P}$, Chisholm B, Fuller J, Marlowe $\mathrm{K}$, et al. Routine evaluation in first-episode psychosis services: feasibility and results from the MiData Project. Soc Psychiatry Psychiatr Epidemiol 2008; 43: 960-7.

39 Turner M, Boden J, Smith-Hammel C, Mulder R. Outcomes for 236 patients from a 2-year early intervention in psychosis service. Acta Psychiatr Scand 2009; 120: 129-37.

40 Brunet $\mathrm{K}$, Birchwood M, Lester $\mathrm{H}$, Thornhill K. Delays in mental health services and duration of untreated psychosis. Psychiatr Bull 2007; 31: 408-10.

41 Rickwood D, Braithwaite V. Social-psychological factors affecting helpseeking for emotional problems. Soc Sci Med 1994; 39: 563-72.

42 Cramer K. Psychological antecedants to help-seeking behaviour: a reanalysis using path-modelling structures. J Couns Psychol 1999; 46: 381-7.

43 Corrigan P, O'Shaughnessy J. Changing mental illness stigma as it exists in the real world. Aust Psychol 2007; 42: 90-7.

44 Sowden A, Stead L. Community interventions for preventing smoking in young people. Cochrane Database Syst Rev 2003; 1: CD001291.

45 Farrelly MC, Davis KC, Haviland ML, Messeri P, Healton CG. Evidence of a dose-response relationship between 'Truth' anti-smoking ads and youth smoking. Am J Public Health 2005; 95: 425-31.

46 Zimmerman R, Palmgreen P, Noar S, Lustria M, Lu H, Horozewski M. Effects of a two-city safer sex mass media campaign targeting high sensation seeking and impulsive decision making young adults. Health Educ Behav 2007; 34: 810-26.

47 Kainth A, Hewitt A, Pattenden J, Sowden A, Duffy S, Watt I, et al. Systematic review of interventions to reduce delay in patients with suspected heart attack. Emerg Med J 2004; 21: 506-8.

48 Turner G. A personal perspective: at the crossroads of heart attack care. Crit Pathw Cardiol 2009; 8: 175-82.

49 Austoker J, Bankhead C, Forbes L, Atkins L, Martin F, Robb K, et al. Interventions to promote cancer awareness and early presentation: systematic review. Br J Cancer 2009; 101: S31-9. 